Research Paper

\title{
Determination of Tobramycin and Vancomycin Exposure Required to Eradicate Biofilms on Muscle and Bone Tissue In Vitro
}

\author{
Vajra Badha1,2, Rex Moore ${ }^{1,2}$, John Heffernan², Paulo Castaneda ${ }^{3}$, Alex McLaren ${ }^{1,2,3}$, Derek Overstreet ${ }^{1,2}{ }^{\circledR}$ \\ 1. School of Biological \& Health Systems Engineering, Arizona State University, Tempe, AZ, USA \\ 2. Sonoran Biosciences, Chandler, AZ, USA \\ 3. University of Arizona College of Medicine, Phoenix, AZ, USA \\ $\bowtie$ Corresponding author: Derek Overstreet; Tel: +1 (480) 389-6413; email: derek.overstreet@sonoranbiosciences.com \\ (c) Ivyspring International Publisher. This is an open access article distributed under the terms of the Creative Commons Attribution (CC BY-NC) license \\ (https://creativecommons.org/licenses/by-nc/4.0/). See http://ivyspring.com/terms for full terms and conditions.
}

Received: 2018.09.04; Accepted: 2018.11.10; Published: 2019.01.01

\begin{abstract}
Background: Bacterial biofilms cause chronic orthopaedic infections. Surgical debridement to remove biofilm can be ineffective without adjuvant local antimicrobials because undetected biofilm fragments may remain in the wound and reestablish the infection if untreated. However, the concentrations and duration of antimicrobial exposure necessary to eradicate bacteria from clinical biofilms remain largely undefined. In this study, we determined the minimum biofilm eradication concentration (MBEC) of tobramycin and vancomycin for bacterial biofilms grown on bone and muscle in vitro.

Methods: Biofilms of pathogens found in musculoskeletal infections (S. aureus, S. epidermidis, E. faecalis, $P$. aeruginosa, and $E$. coli) were established for $72 \mathrm{hr}$ on rabbit muscle and bone specimens in vitro and characterized by SEM imaging and CFU counts. Biofilm-covered tissue specimens were exposed to serial $\log _{2}$ dilutions $(4000-31.25 \mu \mathrm{g} / \mathrm{mL})$ of tobramycin, vancomycin, or a 1:1 combination of both drugs for 6 , 24, or $72 \mathrm{hr}$. Tissues were subcultured following antimicrobial exposure to determine bacterial survival. The breakpoint concentration with no surviving bacteria was defined as the MBEC for each pathogen-antimicrobial-exposure time combination.

Results: All tested pathogens formed biofilm on tissue. Tobramycin/vancomycin $(1: 1)$ was the most effective antimicrobial regimen with MBEC on muscle (10/10 pathogens) or bone (7/10 pathogens) generally in the range of $100-750 \mu \mathrm{g} / \mathrm{mL}$ with 24 or $72 \mathrm{hr}$ exposure. MBEC decreased with exposure time for $53.3 \%$ of biofilms between 6 and $24 \mathrm{hr}, 53.3 \%$ of biofilms between 24 and $72 \mathrm{hr}$, and for $76.7 \%$ of biofilms between 6 and $72 \mathrm{hr}$. MBECs on bone were significantly higher than corresponding MBECs on muscle tissue $(p<0.05)$. In most cases, tissue MBECs were lower compared to previously published MBECs for the same pathogens on polystyrene tissue-culture plates.

Conclusions: The majority of MBECs for orthopaedic infections on bone and muscle are on the order of $100-750 \mu \mathrm{g} / \mathrm{mL}$ of vancomycin+tobramycin when sustained for at least $24 \mathrm{hr}$, which may be clinically achievable using high-dose antimicrobial-loaded bone cement (ALBC).
\end{abstract}

Key words: surgical site infection, bone and joint infection, biofilm susceptibility, antimicrobial susceptibility, local antimicrobial delivery, minimum biofilm eradication concentration

\section{Introduction}

The majority of surgical site infections including bone, joint, and implant-related infections are caused by biofilms, which are communities of bacteria in a polysaccharide matrix that is self-produced following bacterial adhesion to implant or compromised tissue surfaces. ${ }^{1}$ Biofilms are characteristically tolerant to antimicrobials and thus present a major challenge to successful clinical management.2,3 For planktonic infections, the inhibition or reduction of bacteria by systemic antimicrobials combined with a normal host 
immune response can effectively cure the infection. ${ }^{4}$ However, in biofilm-based infections, antimicrobial-tolerant bacteria can survive systemic antimicrobials and evade host immune killing.5,6 Biofilm can become established on compromised host tissue surfaces as an infection progresses and recently, it has become evident that floating bacterial aggregates in synovial fluid can progress to biofilm. ${ }^{7}$ While accepted treatment of established orthopaedic infections includes surgical debridement of infected tissue, these procedures may leave biofilm along the debridement margins or fragments in the surgical wound. 4,8 Retention of biofilm bacteria in the postsurgical wound increases the risk that infection will recur. ${ }^{4}$ Local delivery of antimicrobials is commonly performed with the goal of eradicating bacteria, including any remaining biofilm, after debridement.

The minimum biofilm eradication concentration (MBEC) is the lowest level of an antimicrobial that will kill all bacteria in a biofilm and is often two or more orders of magnitude greater than the minimum inhibitory concentration (MIC) determined for planktonic organisms. ${ }^{9,10}$ Since MBEC drug levels exceed safe systemic levels, antimicrobials are applied directly to the surgical site to maximize efficacy while minimizing systemic toxicity. However, there are few data reporting MBEC for specific pathogens in clinically relevant environments. While it has been long established that biofilms can develop differently depending on the surface on which they are grown, ${ }^{11-15}$ MBECs are generally determined in vitro, frequently using abiotic surfaces, with no standardized methodology. ${ }^{16}$ Previously, we determined MBECs for biofilms established in polystyrene microtiter well plates that were generally on the order of 2,000-16,000 $\mu \mathrm{g} / \mathrm{mL}$ with $24 \mathrm{hr}$ exposure, ${ }^{17}$ although biofilms grown on polystyrene may not be representative of the clinical scenario. Another important consideration is that antimicrobial action is not immediate, and the concentration required to achieve total bacterial kill decreases as the exposure duration increases. 17,18 Again, there are few data characterizing MBECs over clinically relevant antimicrobial exposure times. Prior studies on local antimicrobial delivery report that drug levels in surgical wounds in vivo peak near MBEC levels (>100 $\mu \mathrm{g} / \mathrm{mL}$ ) within the first $24 \mathrm{hr},{ }^{19,20}$ and in some cases are sustained for up to $72 \mathrm{hr} .{ }^{21-23}$

In this work, our primary objective was to determine MBEC using a method that retains critical characteristics of clinical infections, including biofilms of orthopaedic pathogens established on muscle and bone surfaces, drug exposure durations up to $72 \mathrm{hr}$, and clinically relevant antimicrobials. Lacking a validated assay, we developed a protocol for determining MBEC by establishing biofilms on aseptically harvested rabbit muscle and bone specimens in vitro, and treating those biofilms with antimicrobials for 6-72 $\mathrm{hr}$ to simulate the duration of exposure provided by local delivery. Tobramycin and vancomycin were chosen because they are common, clinically used antimicrobials for local delivery in orthopaedics, including in recommended antimicrobial-loaded bone cement (ALBC) formulations. ${ }^{24}$

\section{Methods}

\section{Bacterial Strains}

Ten pathogenic bacterial strains from ATCC (Manassas, VA) were evaluated: 3 S. aureus (ATCC BAA-1556, BAA-1680, 49230), 4 S. epidermidis (35984, 29886, 14990, 700583), and 1 each of E. faecalis (29212), P. aeruginosa (27853) and E. coli (25922). ${ }^{25-28}$ BAA-1556, BAA-1680, and 35984 are multidrug-resistant strains.

\section{Biofilm Growth on Tissue}

Skeletal muscle from the hind limb and cortical bone from the radius were aseptically obtained from New Zealand White rabbits (female, $3.0-3.5 \mathrm{~kg}$, Western Oregon Rabbit Co., Philomath, OR, USA) immediately after euthanasia, and stored frozen at $-20^{\circ} \mathrm{C}$ in sterile centrifuge tubes until use. Tissues were divided to fit into the wells of a 96-well tissue culture plate. Bone specimens (cortical bone of the radius without bone marrow) were cut into $5 \mathrm{~mm}$ long shards (10.6 $\pm 5.7 \mathrm{mg})$; muscle specimens (quadriceps or hamstrings muscles) were cut into cubes approximately $4 \mathrm{~mm}^{3}$ in size $(64.8 \pm 24.6 \mathrm{mg})$.

Biofilm on tissue was produced by a modification of standard in vitro growth assays. ${ }^{29}$ Bacterial suspensions were prepared by overnight culture in tryptic soy broth (TSB, BD, Sparks, MD, USA) then diluted in TSB supplemented with $1 \%$ glucose to $1.5 \times 10^{8} \mathrm{CFUs} / \mathrm{mL}$. Biofilms were grown by placing tissue specimens in the wells of sterile, flat-bottom 96-well tissue culture plates (Celltreat, Shirley, MA, USA), submerging tissue specimens in $200 \mu \mathrm{L}$ of bacterial suspension (one organism used per plate), and incubating for $72 \mathrm{hr}$ at $37^{\circ} \mathrm{C}$. TSB was not exchanged to ensure tissues were exposed to an equivalent density of planktonic bacteria without disruption during the growth phase, and because substantial evaporation did not occur.

\section{Biofilm Characterization}

Tissue-bound biofilms were characterized by counting CFUs using a drop-plate method for each bacterial strain on bone and muscle. ${ }^{30}$ Tissue specimens were rinsed, placed into $1 \mathrm{~mL}$ sterile TSB, 
and bath sonicated ( $35 \mathrm{kHz}$, VWR Aquasonic) for 15 minutes to release adherent bacteria prior to preparing serial dilutions for counting. Biofilms from each strain on bone and muscle were imaged with scanning electron microscopy (SEM). Biofilms were fixed in $2.5 \%$ glutaraldehyde overnight at $4^{\circ} \mathrm{C}$ and stored in $100 \mathrm{mM}$ phosphate buffer. Samples were dehydrated in a water-acetone series, critical point-dried (Balzers CPD 020) with $\mathrm{CO}_{2}$, sputter-coated with gold (Technics Sputter Coater), mounted, and imaged by SEM (JEOL JSM6300; 15 kV; 500X and 4,000X magnification).

\section{MIC, FIC, and MBEC Determination}

Three antimicrobial regimens were investigated: tobramycin alone (TOB; tobramycin sulfate USP, Spectrum Chemical), vancomycin alone (VANC; vancomycin hydrochloride USP, Chem-Impex International Inc.), and tobramycin/vancomycin 1:1 combination by mass (TOB+VANC). For each organism, the fractional inhibitory concentration (FIC) index (dimensionless synergy index : synergistic $\leq 0.5$, indifferent $=0.5-4$, or antagonistic $\geq 4$ ) was determined for tobramycin and vancomycin by checkerboard assay in which 64 concentration combinations were tested. ${ }^{31}$ The minimum inhibitory concentration (MIC) of tobramycin and vancomycin was determined using $8 \log _{2}$ serial dilutions of the respective antimicrobial in the control wells of the checkerboard assay, which is analogous to the CLSI broth microdilution method. ${ }^{32}$

For MBEC determination, antimicrobial solutions in TSB were applied to individual biofilm-tissue specimens in $8 \log _{2}$ serial dilutions from $4,000 \mu \mathrm{g} / \mathrm{mL}$ to $31 \mu \mathrm{g} / \mathrm{mL}$, and in addition 750 $\mu \mathrm{g} / \mathrm{mL}$ and $375 \mu \mathrm{g} / \mathrm{mL}$. Positive controls consisted of biofilms on tissue samples in antibiotic-free medium in the same row of wells to confirm positive cultures. TSB-only negative controls (no tissue specimens or antimicrobials) were included in each plate to confirm sterility and lack of cross-contamination between wells. After $72 \mathrm{hr}$ of biofilm growth on muscle and bone as described above, tissue specimens were transferred into new sterile 96-well plates. For each antimicrobial exposure, tissue type, and exposure time, 11 tissue specimens were submerged in $200 \mu \mathrm{L}$ of TSB (one specimen at each of the 10 antimicrobial concentrations and a TSB-only control) and incubated at $37^{\circ} \mathrm{C}$ for 6, 24, or $72 \mathrm{hr}$ (antimicrobial "exposure time"). For the tobramycin/vancomycin combination group, the reported concentration is the total (additive) concentration, such that the $1,000 \mu \mathrm{g} / \mathrm{mL}$ solution contained $500 \mu \mathrm{g}$ tobramycin plus $500 \mu \mathrm{g}$ vancomycin per $\mathrm{mL}$. In total, 1,800 biofilm-tissue samples (10 bacteria $\times 2$ tissues $\times 3$ regimens $\times 3$ exposure times $\times 10$ concentrations) and 180 control biofilm-tissue samples (10 bacteria $\times 2$ tissues $\times 3$ exposure times $\times 3$ replicates) were tested in this study. From these specimens, $180 \mathrm{MBEC}$ values were determined ( 10 bacteria $\times 3$ antimicrobial regimens $\times 3$ durations $\times 2$ tissue types), one MBEC value from each series of 10 samples.

After antimicrobial exposure, tissue specimens were gently rinsed at least 4 times with sterile TSB to thoroughly remove the antimicrobials, preventing residual antibacterial suppression of viable bacteria in subcultures. Viable bacteria were then detected by subculture. The tissue specimens with their biofilms intact were placed in new tubes containing $3 \mathrm{~mL} \mathrm{TSB}$, bath sonicated (35 kHz, VWR Aquasonic) for 15 minutes to facilitate release of bacteria from the biofilm and then incubated at $37^{\circ} \mathrm{C}$ for 21 days to ensure detection of any slow-growing bacteria. Bacteria surviving antimicrobial exposure were identified by turbidity in the liquid subculture.

The MBEC was defined as the lowest antimicrobial concentration of 10 tested (breakpoint concentration) that was associated with no surviving bacteria (no turbidity). The breakpoint concentration was classified as "clean" when multiple sequential negative subcultures were observed immediately above the highest concentration yielding a positive subculture. If all subcultures were turbid, the MBEC was recorded as $>4,000 \mu \mathrm{g} / \mathrm{mL}$. If all subcultures containing antimicrobials were not turbid, the MBEC was recorded as $\leq 31 \mu \mathrm{g} / \mathrm{mL}$. MBEC values of 1,000 $\mu \mathrm{g} / \mathrm{mL}$ or greater were defined as "extreme" because $1,000 \mu \mathrm{g} / \mathrm{mL}$ is estimated to be near the maximum exposure achievable by local delivery over 3 days. ${ }^{21-23}$ The number of strains having extreme MBEC for each antimicrobial treatment, exposure time, and tissue type was reported. Samples from one positive culture per organism were sent to a third-party diagnostic laboratory (Antech Diagnostics, Phoenix, AZ) for aerobic culture and identification to confirm that regrowth was due to the initial organism.

Statistical significance $(\alpha=0.05)$ of differences in CFUs between growth substrates was determined by two-tailed paired t-test. Differences in MBEC between growth substrates, antimicrobial exposure times $(6 \mathrm{hr}$, $24 \mathrm{hr}, 72 \mathrm{hr}$ ), and against MIC values were determined by sign test. Differences in the frequency of extreme MBEC values compared across antimicrobial regimens and tissue types were determined by McNemar's test.

\section{Ethics}

All research involving animals was approved by the IACUC at St. Joseph's Hospital and Medical Center (Phoenix, AZ) and conducted in compliance 
with all relevant institutional and national standards for animal care and experimentation. Tissue specimens used in this study were collected after euthanasia of rabbits used in separate studies.

\section{Results}

\section{MIC and FIC Determination}

Among planktonic organisms, S. epidermidis 35984 and 29886 were observed to have high MIC (16 $\mu \mathrm{g} / \mathrm{mL}$ ) to tobramycin (Table 1 ), while the two Gram-negative microorganisms, P. aeruginosa 27853 and E. coli 25922, were expectedly not inhibited by vancomycin at any concentration tested (MIC > 64 $\mu \mathrm{g} / \mathrm{mL}$ ). For all other antimicrobial/microorganism pairs tested, the MIC was in the range of 0.125-8 $\mu \mathrm{g} / \mathrm{mL}$ (Table 1). In checkerboard assays, synergy between tobramycin and vancomycin only occurred for S. epidermidis 29886 (FIC index 0.18) and there was no antagonism between tobramycin and vancomycin for any of the organisms.

Table 1. Minimum inhibitory concentration (MIC) and fractional inhibitory concentration (FIC) index for musculoskeletal associated biofilms. FIC index values indicate synergistic $(\leq 0.5)$, indifferent (0.5-4), or antagonistic $(\geq 4)$ drug interactions.

\begin{tabular}{llll}
\hline Species / ATCC\# & $\begin{array}{l}\text { Tobramycin } \\
(\mu \mathrm{g} / \mathrm{ml})\end{array}$ & $\begin{array}{l}\text { Vancomycin } \\
(\mu \mathrm{g} / \mathrm{ml})\end{array}$ & $\begin{array}{l}\text { Tobramycin/Vancomycin } \\
1: 1 \text { Combination }\end{array}$ \\
\cline { 4 - 4 } & & 2 & FIC index \\
\hline S. aureus BAA-1556 & 0.25 & 2 & 1.20 \\
S. aureus BAA-1680 & 0.5 & 2 & 1.34 \\
S. aureus 49230 & 0.5 & 8 & 0.81 \\
S. epidermidis 35984 & 16 & 4 & 0.56 \\
S. epidermidis 29886 & 16 & 4 & 0.18 \\
S. epidermidis 700583 & 0.125 & 4 & 1.08 \\
S. epidermidis 14990 & 0.25 & 1 & 1.07 \\
E. faecalis 29212 & 2 & $>64$ & 1.69 \\
P. aeruginosa 27853 & 0.5 & $>64$ & 0.89 \\
E. coli 25922 & 2 & & 0.83 \\
\hline
\end{tabular}

\section{Biofilm Characterization}

CFU counts and SEM images confirmed biofilm formation on all specimens (Figure 1). Biofilms showed a variety of phenotypes which in many cases included widespread EPS formation on tissue surfaces (Figures 1A). Representative images of biofilms of all microorganisms on muscle and bone at 500X and 4,000X are included in the supplemental data. (Figures S1 and S2). EPS appears as the filamentous, sheet-like, or granular extracellular structures on tissue surfaces that are observed between individual bacteria, or those in which bacteria are embedded. Qualitatively, biofilm coverage appeared more extensive on muscle than bone. All biofilms appeared monomicrobial and consistent with the morphology of the study organism. CFUs per specimen were between $8.35 \times 10^{3}$ $-1.12 \times 10^{8}$ on bone and $1.19 \times 10^{4}-4.85 \times 10^{8}$ on muscle
(Figure 1B); CFUs for biofilms on bone and muscle specimens were not significantly different $(p=0.2742$; two-tailed paired t-test).

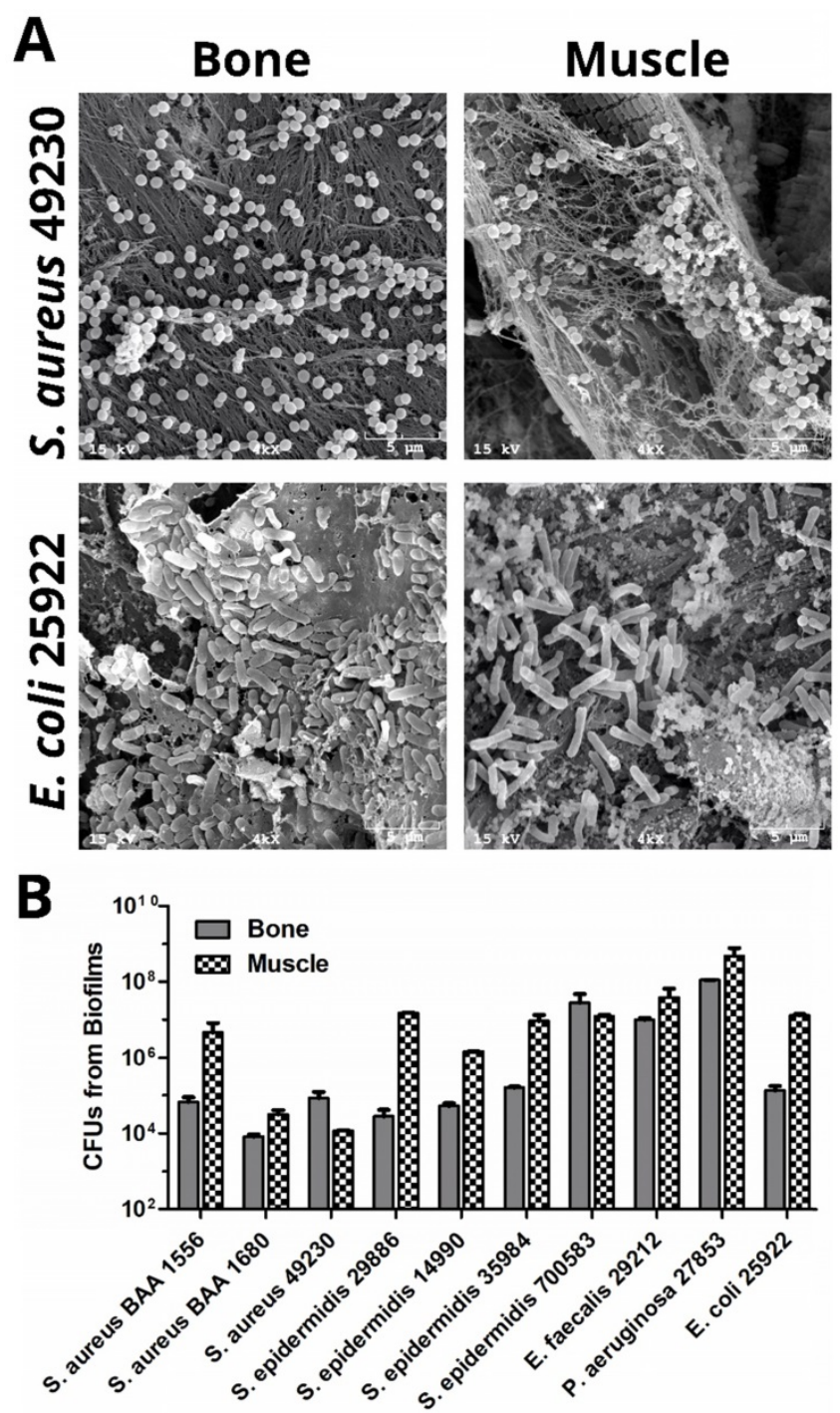

Figure 1. Biofilm characterization. (A) SEM analysis and (B) CFU counts following 72 $\mathrm{hr}$ biofilm growth on bone and muscle tissue. SEM images were taken at $4000 \mathrm{X}$ magnification and show two representative biofilm strains (all additional strains in Supplemental Figures S1 and S2). CFUs are presented as mean values \pm standard deviation.

\section{MBEC Determination}

MBECs for tobramycin and vancomycin against all 10 bacterial biofilms on muscle and bone were greater than their respective MIC values $(p<0.0001$; Figure 2, Table S1). All positive subcultures tested were confirmed as the original organism only. Approximately $90 \%$ of positive subcultures occurred within 5-7 days of subculture and all positive subcultures became turbid by 14 days. Across all treatment combinations (i.e., for a given microorganism, drug level and exposure time, and tissue), MBEC decreased with increasing antimicrobial exposure time $(p=0.0003,6$ vs. $24 \mathrm{hr} ; \mathrm{p}$ 
$=0.0124,24 \mathrm{hr}$ vs. $72 \mathrm{hr}$ ). MBEC decreased in $53.3 \%$ of cases between 6 and $24 \mathrm{hr}$, in another $53.3 \%$ of cases between 24 and $72 \mathrm{hr}$, and in $76.7 \%$ of cases between 6 and $72 \mathrm{hr}$. Clean breakpoints were observed in $159 / 180(88.3 \%)$ of the subculture series. Among the 1,800 total subcultures, 36 of 1800 subcultures $(2.0 \%)$ were identified as false negatives (negative subculture at a concentration between sequential positive subcultures) and 6 of 1800 subcultures (0.3\%) were identified as false positives (positive subculture between sequential negative subcultures).

\section{Extreme MBEC}

Extreme MBEC values $(\geq 1,000 \mu \mathrm{g} / \mathrm{mL})$ were observed less frequently for the combination of tobramycin/vancomycin (13/60) compared to tobramycin alone $(21 / 60, \mathrm{p}=0.0159)$ or vancomycin alone (49/60, p < 0.0001) (Table 2). Extreme MBECs across all exposure times for the tobramycin/vancomycin combination occurred more frequently for biofilms on bone compared to muscle $(\mathrm{p}<0.0001)$.

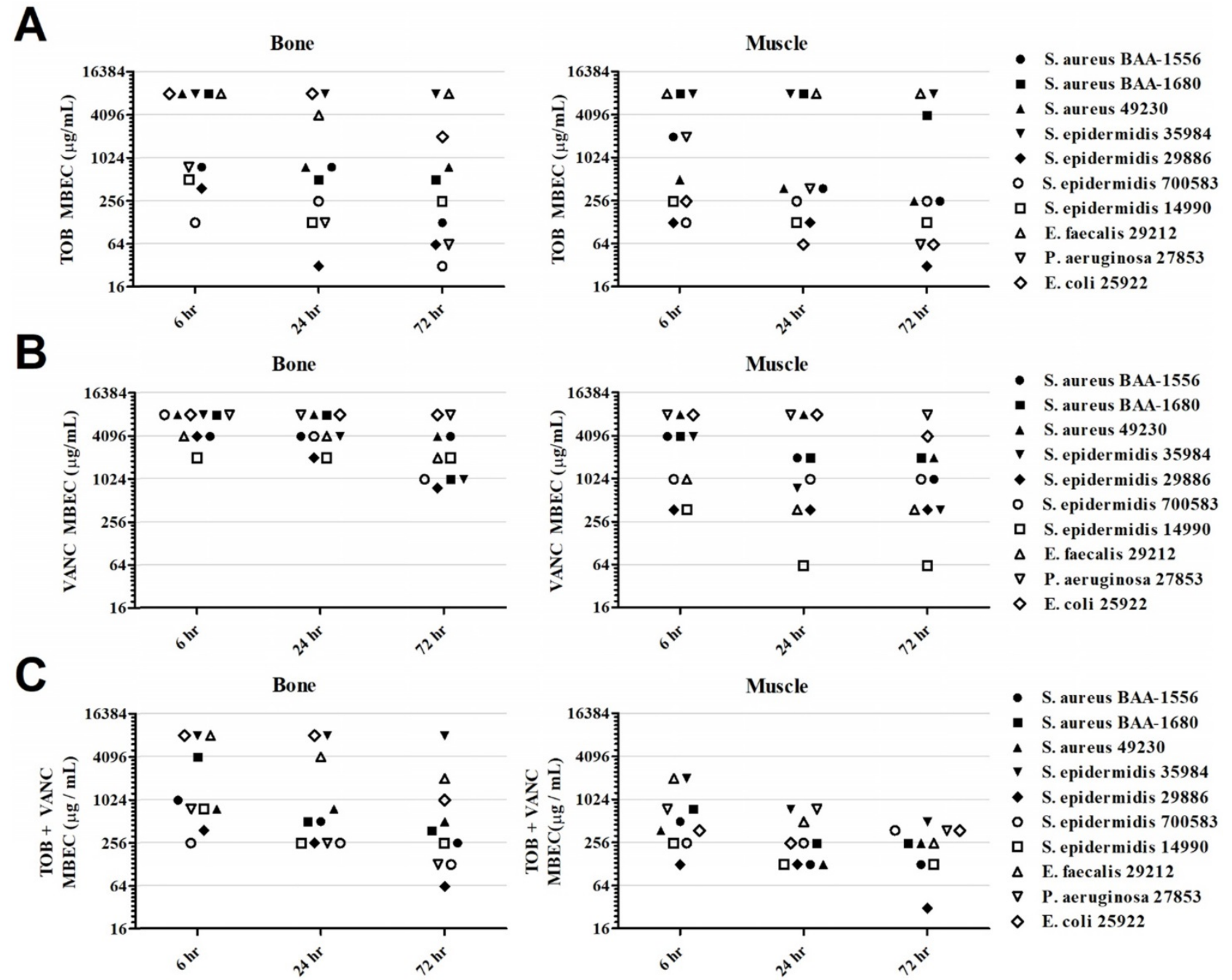

Figure 2. MBEC for 10 musculoskeletal biofilms on bone (left column) and muscle (right column) tissue treated with (A) tobramycin, (B) vancomycin, or (C) tobramycin/vancomycin combination for 6 to $72 \mathrm{hr}$ (see also Table S1).

Table 2. Strains with extreme minimum biofilm eradication concentration (MBEC) for musculoskeletal biofilms on bone and muscle tissue.

\begin{tabular}{|c|c|c|c|c|c|c|c|}
\hline & & Bone & & & Muscle & & \\
\hline & $\begin{array}{l}\text { Exposure } \\
\text { Time }\end{array}$ & $\begin{array}{l}\text { Tobramycin } \\
(\mu \mathrm{g} / \mathrm{ml})\end{array}$ & $\begin{array}{l}\text { Vancomycin } \\
(\mu \mathrm{g} / \mathrm{ml})\end{array}$ & $\begin{array}{l}\text { 1:1 Combination } \\
(\mu \mathrm{g} / \mathrm{ml})\end{array}$ & $\begin{array}{l}\text { Tobramycin } \\
(\mu \mathrm{g} / \mathrm{ml})\end{array}$ & $\begin{array}{l}\text { Vancomycin } \\
(\mu \mathrm{g} / \mathrm{ml})\end{array}$ & $\begin{array}{l}\text { 1:1 Combination } \\
(\mu \mathrm{g} / \mathrm{ml})\end{array}$ \\
\hline \multirow{3}{*}{$\begin{array}{l}\text { Strains with extreme } \\
\operatorname{MBEC}(\geq 1,000 \mu \mathrm{g} / \mathrm{mL})\end{array}$} & $6 \mathrm{hr}$ & $5 / 10$ & $10 / 10$ & $5 / 10$ & $5 / 10$ & $8 / 10$ & $2 / 10$ \\
\hline & $24 \mathrm{hr}$ & $3 / 10$ & $10 / 10$ & $3 / 10$ & $3 / 10$ & $6 / 10$ & $0 / 10$ \\
\hline & $72 \mathrm{hr}$ & $3 / 10$ & $9 / 10$ & $3 / 10$ & $3 / 10$ & $6 / 10$ & $0 / 10$ \\
\hline
\end{tabular}




\section{Discussion}

The primary goal of this work was to identify the antimicrobial concentration and exposure time necessary for two commonly used antimicrobial agents to eradicate a range of orthopaedic pathogens from biofilms formed on clinically relevant tissue surfaces. There are no clinically validated assays for antimicrobial susceptibility of bacteria within biofilm. The most common methods entail exposure to antimicrobials for up to 24 hours following biofilm growth either in conventional tissue culture plates ${ }^{33}$ or on the pegs of the Calgary biofilm device. ${ }^{16,34}$ These assays do not account for the complex surfaces of soft tissue and bone, including bone's internal surfaces (Haversian canals, canaliculi), or the three-dimensional structures that biofilms grow on in musculoskeletal infections. We chose to evaluate biofilm antimicrobial susceptibility on muscle and bone tissue specimens because they provide the physical and chemical attributes of infected tissue fragments which could be present in a post-debridement wound. This work produced several clinically important findings: 1) MBECs of biofilms growing on muscle and bone using 1:1 tobramycin/vancomycin combination therapy were generally in the range of $100-750 \mu \mathrm{g} / \mathrm{mL}$ after $24 \mathrm{hr}$ antimicrobial exposure: $750 \mu \mathrm{g} / \mathrm{mL}$ for $24 \mathrm{hr}$ was sufficient to kill all the bacteria in 17 of 20 biofilms; 2) MBEC varies based on the growth substrate; 3) a clinically important decrease in MBECs occurs with increasing antimicrobial exposure time, especially between 6 and $24 \mathrm{hr}$.

The method we developed for MBEC determination produced reasonably consistent samples with extensive biofilm (Figure 1, Supplemental Figures S1 and S2). Still, the methodology is new and as such has some limitations. First, biofilm maturity was not characterized. As biofilms develop, cell replication and metabolic activity decrease which produces a corresponding decrease in antimicrobial susceptibility. ${ }^{35}$ Although the antimicrobial susceptibility versus biofilm growth time will differ between organisms, biofilm growth was held constant at $72 \mathrm{hr}$ to standardize the assay. Second, we elected to not replace the liquid medium during biofilm growth or during antimicrobial exposure. In each case, evaporation was minimal and the tissue samples remained fully submerged. We do not believe that nutrient deprivation explains the decrease in MBEC over exposure time because biofilms that would have been the most susceptible to nutrient deprivation (positive controls and biofilms exposed to low antimicrobial concentrations) reliably survived and re-grew after $72 \mathrm{hr}$ exposure. Third, we used small tissue samples with variable size for
MBEC determination. This work was not intended to test antimicrobial tissue penetration or treatment of inadequately debrided infections, nor is it intended to challenge thorough surgical debridement as a requirement of appropriate treatment. Small tissue specimens $\left(10-60 \mathrm{~mm}^{3}\right)$ were used to ensure thorough antimicrobial penetration and to approximate tissue fragments which could remain in a wound following intralesional debridement. As mentioned above, despite variable specimen size, subculture results within each series were in complete agreement $88.3 \%$ of the time. While larger tissue specimens would have allowed for a greater number of bacteria to adhere to the surface, we evaluated the presence or absence of bacteria rather than counting the number of surviving bacteria, so the total number of bacteria is less important. Fourth, we used bath sonication to facilitate liberation of bacteria adhered to tissue in biofilm as previously described in clinical practice, ${ }^{36}$ but this procedure has also been reported to have bactericidal effects. ${ }^{37}$ In this assay, sonication would have to eradicate nearly all bacteria to introduce meaningful error into the MBEC determination. However, it may have negatively affected CFU quantification. Fifth, the method entails submerging tissues for subculture which were previously stored in up to $4,000 \mu \mathrm{g} / \mathrm{mL}$ of antimicrobials, and we did not measure the antimicrobial concentration in the subculture media, posing a risk that regrowth in subcultures could be inhibited. However, the rinsing method that we used appears sufficient because we obtained positive cultures after short exposure times for samples incubated in $4,000 \mu \mathrm{g} / \mathrm{mL}$, indicating that antimicrobials in these samples were removed to sub-MIC levels, allowing regrowth.

This study also has some additional limitations pertaining to its scope. First, MBEC measurements were not repeated. In previous work, we determined MBEC in triplicate and observed no more than one interval of difference in the MBEC value between replicates. ${ }^{33}$ In the present study, each MBEC value was derived from a series of 10 individual subcultures in addition to 2 controls to verify bacterial viability and lack of cross-contamination. The binary outcomes for each subculture collectively indicate a specific breakpoint within the series, and clean breakpoints were observed in $88.3 \%$ of the subculture series. Moreover, across the 1800 subcultures only $2 \%$ were identified as false negatives, and $0.3 \%$ were identified as false positives. The high frequency of clean breakpoints among subculture series suggests that the sample-to-sample variability was low and the MBECs are reasonably accurate despite a lack of replication. It is generally standard protocol to determine MIC in a single assay, and in reference data these are 
commonly reported as a range, not a single number. This reflects that there is some inherent variability in microbiological experiments despite rigorous controls. Likewise, MBEC values represent ranges of antimicrobial susceptibility and likely will vary within about one interval between experiments. Second, the scope of this work was limited to five bacterial species, three of which were represented by only one strain. The bacteria selected were intended to provide a clinically representative spectrum of pathogens and were originally isolated from clinical infections. There are more species of interest for future work, and we acknowledge that assaying biofilms recovered from clinical infections might be more clinically relevant. Third, we did not measure MBEC for biofilms growing on implant materials. Implant material surfaces will need to be assessed using the same methodology. Fourth, we chose to evaluate two antimicrobials, tobramycin and vancomycin, alone and in combination due to their long history of use in local delivery in orthopaedics and their broad spectrum coverage against orthopaedic pathogens. ${ }^{24}$ Other antimicrobials may also be appropriate for eradication of bacteria from biofilms in orthopaedic infections and are of interest for testing in future work. We also did not measure antimicrobial concentrations after exposure because both tobramycin ${ }^{38-40}$ and vancomycin ${ }^{41-44}$ are waterand heat-stable under similar conditions and are not metabolized. Finally, we did not investigate the risk for local tissue toxicity that may be associated with such high doses of antimicrobials as has been reported in in vitro studies. ${ }^{45}$

Our current and previously published data ${ }^{33}$ fit a consistent pattern where MBEC is higher for shorter exposure times and lower for longer exposure times (Figure 2, Table S1). For more than half of the pathogens tested, MBEC after $24 \mathrm{hr}$ exposure was less than that after $6 \mathrm{hr}$ exposure. Longer exposure times up to $72 \mathrm{hr}$ were associated with lower MBEC values, but to a lesser degree. Overall, tissue MBEC for tobramycin/vancomycin was in the range of 100-750 $\mu \mathrm{g} / \mathrm{mL}$ total concentration at $24 \mathrm{hr}$ exposure, and only 3 of 20 MBEC values across all conditions were characterized as extreme (all on bone). Considering this, we estimate that drug levels of $100-750 \mu \mathrm{g} / \mathrm{mL}$ sustained for $24 \mathrm{hr}$ may be an appropriate and realistic goal for local delivery in treatment of orthopaedic infection.

Antimicrobials released from ALBC or provided by local application of vancomycin powder reach peak local tissue concentrations within 6-24 hr after dosing. 19,22,23,46 In a clinical study, low-dose ALBC spacers (2.5 g antimicrobials per $40 \mathrm{~g}$ batch of cement) were reported to achieve mean concentrations of 196 $\mu \mathrm{g} / \mathrm{mL}$ in wound drains at $24 \mathrm{hr} .{ }^{22}$ Moreover, we have reported that antimicrobial release from high-dose ALBC spacers ( $10 \mathrm{~g}$ antimicrobials per $40 \mathrm{~g}$ batch) is approximately 25 -fold greater than from low-dose ALBC (1 g per $40 \mathrm{~g}$ batch) and 3.4-fold over medium-dose ALBC ( $5 \mathrm{~g}$ per $40 \mathrm{~g}$ batch) in the first 24 $\mathrm{hr}$ in vitro. ${ }^{23}$ Therefore, ALBC spacers, especially those with $5 \mathrm{~g}$ or more of antimicrobials per batch, are likely capable of achieving the MBEC levels we have identified in this work $(100-750 \mu \mathrm{g} / \mathrm{mL})$ covering a wide variety of common microorganisms at $24 \mathrm{hr}$ in clinical practice. Similarly, clinical use of intrawound vancomycin powder in total hip and knee arthroplasties was reported to provide average wound levels of $207 \pm 317 \mu \mathrm{g} / \mathrm{mL}$ after $24 \mathrm{hr} .{ }^{47}$ Some investigational therapies have also been reported to be capable of providing improved antimicrobial exposure profiles compared to ALBC and intrawound antimicrobial powder. ${ }^{48,49}$ Based on these reports of local delivery, maintaining levels over $100 \mu \mathrm{g} / \mathrm{mL}$ for 24 hours is a reasonable expectation of high-dose ALBC, but attaining levels exceeding $1,000 \mu \mathrm{g} / \mathrm{mL}$ for 24 hours or peak levels approaching $4,000 \mu \mathrm{g} / \mathrm{mL}$, as required for 15 of 40 of our monotherapy specimens at 6 hours, may not be. Determination of appropriate local antimicrobial doses requires clinical judgment and an understanding of what levels are possible in post-debridement sites.

While biofilm susceptibility on different surfaces has been reported previously, 11-15,18 our data confirm that MBEC varies depending on the growth substrate. Prior work has shown that biofilms established in vitro on bone tissue exhibit higher tolerance to tobramycin and vancomycin than biofilms on PMMA and PTFE biomaterials or planktonic cultures. ${ }^{14}$ Here, we found that MBECs of biofilms on muscle are generally lower than on bone (Figure 2). Comparing results from 5 strains (BAA-1556, 49230, 35984, 27853, and 25922) common to this work and previously published MBEC data for biofilms grown on polystyrene for a shorter growth time $(24 \mathrm{hr}),{ }^{33}$ we found that MBECs for biofilms grown on polystyrene were not predictive of the MBEC for the same pathogen grown on muscle or bone (Figure 3). MBECs on tissue were lower than on polystyrene, with the exceptions of $S$. epidermidis 35984 on muscle and E. coli 25922 on muscle and bone. Differences between polystyrene and either muscle or bone were not statistically significant $(p=0.5271$ polystyrene vs. bone; $\mathrm{p}=0.0578$ polystyrene vs. muscle), likely due to lack of statistical power.

In our view, the MBEC levels measured here should not be considered equivalent to what is required for clinical cure because clinical local delivery may not sufficiently access all bacteria, and biofilms in our assay are grown in ideal growth 


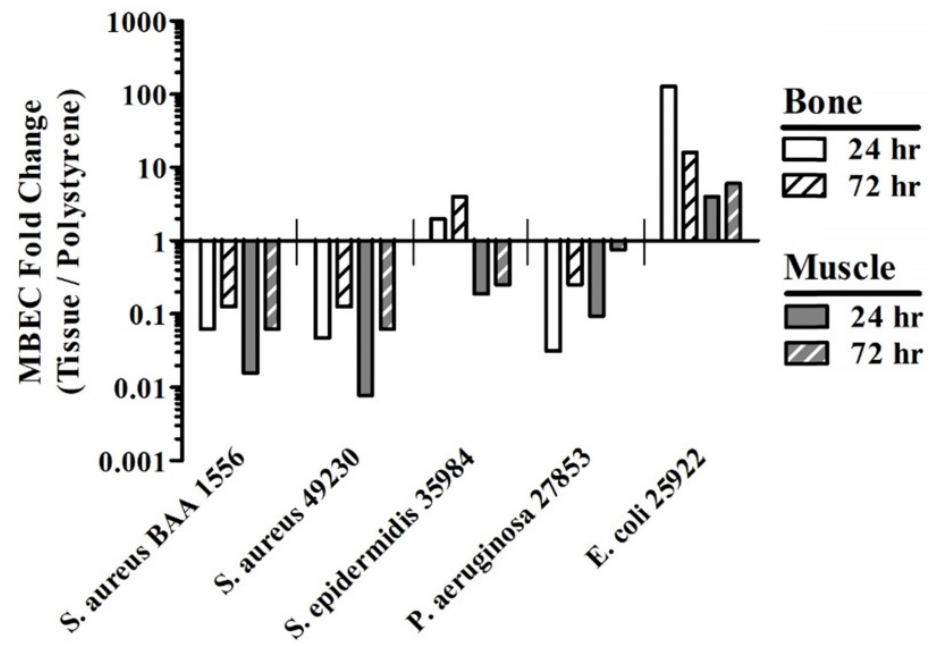

Figure 3. Fold change in MBEC for musculoskeletal biofilms on muscle or bone treated with tobramycin/vancomycin compared to MBEC on polystyrene.

conditions without challenge from the immune system. In a prior study of osteomyelitis treatment in rabbits, we found that lower concentrations on the order of MIC (provided by systemic antimicrobials or low-dose ALBC) were effective following intralesional debridement in about half of the rabbits. ${ }^{50}$ The successful outcomes were likely attributable to the host response in rabbits. It is widely accepted that biofilms in clinical infections generally cannot be successfully eradicated with systemic antimicrobials alone, and local antimicrobial delivery (which provides levels in excess of MIC) is a necessary component of clinical treatment of established infections. ${ }^{4,51}$ Much higher delivery (estimated in excess of MBEC levels) was required for treatment success in all rabbits. Therefore, the drug levels needed for reliable therapeutic success are likely substantially higher than MIC, but may be lower than the MBEC values measured for tissue-based biofilms reported here.

Our data identify outlier biofilms having extreme MBECs $(\geq 1000 \mu \mathrm{g} / \mathrm{mL})$ at $24 \mathrm{hr}$ and longer exposure times. While many of the MBECs $(\leq 750$ $\mu \mathrm{g} / \mathrm{mL}$ for $24 \mathrm{hr}$ ) are likely achievable by high-dose local delivery, outliers with extreme MBECs to tobramycin and vancomycin exist, even for the more broadly effective combination therapy. Three of 10 bacterial strains formed biofilm on bone with MBEC $\geq$ $4,000 \mu \mathrm{g} / \mathrm{mL}$ at $24 \mathrm{hr}$ exposure and $\geq 1000 \mu \mathrm{g} / \mathrm{mL}$ at $72 \mathrm{hr}$ exposure. It may not be possible to achieve such high antimicrobial levels throughout a post-debridement site in a clinical case, raising the possibility of failures based on biofilms with extreme MBEC for a given antimicrobial regimen. Thus, there remains a need for a clinical assay that provides reliable susceptibility data in cases of treatment failure to inform antimicrobial selection.
Another notable result of our work was that antimicrobial-bacterium pairs with low MICs can have extremely high MBECs. For example, the two MRSA strains (BAA-1556 and BAA-1680) on bone and muscle exhibited extreme MBEC for vancomycin at all exposure times despite both having comparatively low MIC of $2 \mu \mathrm{g} / \mathrm{mL}$. In addition, S. epidermidis 29886 was the only strain that exhibited an FIC index indicative of synergy between tobramycin and vancomycin, but synergy observed in planktonic culture was not reproduced in biofilm culture (Table S1). $S$. aureus BAA-1680 biofilm on muscle was the only case where the drugs appeared to produce a synergistic result, but this planktonic organism had an FIC index of 1.34, indicating indifferent effects. Therefore, these data collectively suggest that antimicrobial susceptibility in planktonic cultures cannot be presumed to predict biofilm susceptibility.

In conclusion, MBECs determined using biofilms grown on tissue may be more representative of MBECs of pathogens in clinical musculoskeletal infections than MBECs determined using previously reported methods for determining biofilm susceptibility. The MBECs for common musculoskeletal pathogens are far greater than the concentrations achievable by systemic administration, but the majority are likely achievable by local delivery techniques providing tissue levels on the order of $100-750 \mu \mathrm{g} / \mathrm{mL}$ sustained for at least $24 \mathrm{hr}$.

\section{Supplementary Material}

Supplementary figures and tables.

http://www.jbji.net/v04p0001s1.pdf

\section{Acknowledgements}

This work was supported by the National Institute Of Arthritis And Musculoskeletal And Skin Diseases of the National Institutes of Health (R44AR070685). The content is solely the responsibility of the authors and does not necessarily represent the official views of the National Institutes of Health.

\section{Competing Interests}

DO and AM own stock in Sonoran Biosciences, which is developing sustained release antimicrobial formulations for treatment and prevention of biofilm-based infections. DO, VB, RM and JH are or have been employees of Sonoran Biosciences. AM has served as a paid consultant to Sonoran Biosciences. 


\section{References}

1. Hall-Stoodley L, Stoodley P, Kathju S, et al. Towards diagnostic guidelines for biofilm-associated infections. FEMS Immunol Med Microbiol. 2012; 65: 127-145. doi:10.1111/j.1574-695X.2012.00968.x

2. Costerton JW, Stewart PS, Greenberg EP. Bacterial Biofilms: A Common Cause of Persistent Infections. Science. 1999; 284: 1318-1322. doi:10.1126/science.284.5418.1318

3. Donlan RM, Costerton JW. Biofilms: Survival Mechanisms of Clinically Relevant Microorganisms. Clin Microbiol Rev. 2002; 15: 167-193. doi:10.1128/CMR.15.2.167-193.2002

4. Costerton JW. Biofilm Theory Can Guide the Treatment of Device-Related Orthopaedic Infections. Clin Orthop Relat Res. 2005; $437: 7$.

5. Lewis K. Riddle of Biofilm Resistance. Antimicrob Agents Chemother. 2001; 45: 999-1007. doi:10.1128/AAC.45.4.999-1007.2001

6. Lewis K. Persister Cells. Annu Rev Microbiol. 2010; 64: 357-372. doi:10.1146/annurev.micro.112408.134306

7. Dastgheyb S, Parvizi J, Shapiro IM, et al. Effect of Biofilms on Recalcitrance of Staphylococcal Joint Infection to Antibiotic Treatment. J Infect Dis. 2015; 211: 641-650. doi:10.1093/infdis/jiu514

8. Osmon DR, Berbari EF, Berendt AR, et al. Diagnosis and management of prosthetic joint infection: clinical practice guidelines by the Infectious Diseases Society of America. Clin Infect Dis Off Publ Infect Dis Soc Am. 2013; 56: e1-e25. doi:10.1093/cid/cis803

9. Olson ME, Ceri H, Morck DW, et al. Biofilm bacteria: formation and comparative susceptibility to antibiotics. Can J Vet Res Rev Can Rech Vét. 2002; 66: 86-92.

10. Patel R. Biofilms and antimicrobial resistance. Clin Orthop. 2005; : 41-47.

11. Teughels W, Van Assche N, Sliepen I, et al. Effect of material characteristics and/or surface topography on biofilm development. Clin Oral Implants Res. 2006; 17 Suppl 2: 68-81. doi:10.1111/j.1600-0501.2006.01353.x

12. Morgan TD, Wilson $M$. The effects of surface roughness and type of denture acrylic on biofilm formation by Streptococcus oralis in a constant depth film fermentor. J Appl Microbiol. 2001; 91: 47-53. doi: 10.1046/j.1365-2672.2001.01338.x

13. Patel JD, Ebert M, Ward R, et al. S. epidermidis biofilm formation: effects of biomaterial surface chemistry and serum proteins. J Biomed Mater Res A. 2007; 80: 742-751. doi:10.1002/jbm.a.31103

14. Webb LX, Holman J, de Araujo B, et al. Antibiotic resistance in staphylococci adherent to cortical bone. J Orthop Trauma. 1994; 8: 28-33.

15. Gristina AG, Jennings RA, Naylor PT, et al. Comparative in vitro antibiotic resistance of surface-colonizing coagulase-negative staphylococci. Antimicrob Agents Chemother. 1989; 33: 813-816. doi:10.1128/AAC.33.6.813

16. Azeredo J, Azevedo NF, Briandet R, et al. Critical review on biofilm methods. Crit Rev Microbiol. 2017; 43: 313-351. doi:10.1080/1040841X.2016.1208146

17. Castaneda P, McLaren A, Tavaziva G, et al. Biofilm Antimicrobial Susceptibility Increases With Antimicrobial Exposure Time. Clin Orthop Relat Res. 2016; 474: 1659-1664. doi:10.1007/s11999-016-4700-z

18. Post V, Wahl P, Richards RG, et al. Vancomycin displays time-dependent eradication of mature Staphylococcus aureus biofilms: VANCOMYCIN-MEDIATED BIOFILM ERADICATION. J Orthop Res. 2017; 35: 381-388. doi:10.1002/jor.23291

19. Giers MB, McLaren AC, Plasencia JD, et al. Spatiotemporal quantification of local drug delivery using MRI. Comput Math Methods Med. 2013; 2013: 149608. doi:10.1155/2013/149608

20. Hayes GM, Gibson TWG, Moens NMM, et al. Intra-articular pharmacokinetics of a gentamicin impregnated collagen sponge in the canine stifle: an experimental study. Vet Surg VS. 2014; 43: 166-173. doi:10.1111/j.1532-950X.2014.12115.x

21. Nelson CL, Hickmon SG, Skinner RA. Treatment of experimental osteomyelitis by surgical debridement and the implantation of bioerodable, polyanhydride-gentamicin beads. J Orthop Res. 1997; 15: 249-255.

22. Anagnostakos K, Wilmes $\mathrm{P}$, Schmitt E, et al. Elution of gentamicin and vancomycin from polymethylmethacrylate beads and hip spacers in vivo. Acta Orthop. 2009; 80: 193-197. doi:10.3109/17453670902884700

23. Goltzer O, McLaren A, Overstreet D, et al. Antimicrobial Release From Prefabricated Spacers Is Variable and the Dose Is Low. Clin Orthop Relat Res. 2015; . doi:10.1007/s11999-015-4161-9

24. Hanssen AD, Spangehl MJ. Practical applications of antibiotic-loaded bone cement for treatment of infected joint replacements. Clin Orthop. 2004; : 79-85.

25. Corvec S, Portillo ME, Pasticci BM, et al. Epidemiology and new developments in the diagnosis of prosthetic joint infection. Int J Artif Organs. 2012; : 0-0. doi:10.5301/ijao.5000168

26. Campoccia D, Montanaro L, Arciola CR. The significance of infection related to orthopedic devices and issues of antibiotic resistance. Biomaterials. 2006; 27: 2331-2339. doi:10.1016/j.biomaterials.2005.11.044

27. Hansen EN, Adeli B, Kenyon R, et al. Routine Use of Antibiotic Laden Bone Cement for Primary Total Knee Arthroplasty: Impact on Infecting Microbial Patterns and Resistance Profiles. J Arthroplasty. 2014; 29: 1123-1127. doi:10.1016/j.arth.2013.12.004

28. Berbari EF, Marculescu C, Sia I, et al. Culture-Negative Prosthetic Joint Infection. Clin Infect Dis. 2007; 45: 1113-1119. doi:10.1086/522184

29. Djordjevic D, Wiedmann M, McLandsborough LA. Microtiter Plate Assay for Assessment of Listeria monocytogenes Biofilm Formation. Appl Env Microbiol. 2002; 68: 2950-2958. doi:10.1128/AEM.68.6.2950-2958.2002
30. Miles AA, Misra SS, Irwin JO. The estimation of the bactericidal power of the blood. Epidemiol Infect. 1938; 38: 732-749. doi:10.1017/S002217240001158X

31. Jenkins SG, Schuetz AN. Current Concepts in Laboratory Testing to Guide Antimicrobial Therapy. Mayo Clin Proc. 2012; 87: 290-308. doi:10.1016/j.mayocp.2012.01.007

32. M07-A10: Methods for Dilution Antimicrobial Susceptibility Tests for Bacteria That Grow Aerobically, 10th Edition. Clinical and Laboratory Standards Institute; 2018

33. Castaneda P, McLaren A, Tavaziva G, et al. Biofilm Antimicrobial Susceptibility Increases With Antimicrobial Exposure Time. Clin Orthop Relat Res. 2016; . doi:10.1007/s11999-016-4700-z

34. Ceri H, Olson ME, Stremick C, et al. The Calgary Biofilm Device: new technology for rapid determination of antibiotic susceptibilities of bacterial biofilms. J Clin Microbiol. 1999; 37: 1771-1776.

35. Wolcott RD, Rumbaugh KP, James G, et al. Biofilm maturity studies indicate sharp debridement opens a time- dependent therapeutic window. J Wound Care. 2010; 19: 320-328.

36. Trampuz A, Piper KE, Jacobson MJ, et al. Sonication of removed hip and knee prostheses for diagnosis of infection. N Engl J Med. 2007; 357: 654-663. doi:10.1056/NEJMoa061588

37. Joyce E, Al-Hashimi A, Mason TJ. Assessing the effect of different ultrasonic frequencies on bacterial viability using flow cytometry. J Appl Microbiol. 2011; 110: 862-870. doi:10.1111/j.1365-2672.2011.04923.x

38. Bergstrom RF, Fites AL, Lamb JW. Stability of parenteral solutions of tobramycin sulfate. Am J Hosp Pharm. 1975; 32: 887-888.

39. Law S. Stability of Preservative-Free Tobramycin in Half-Normal Saline. Can J Hosp Pharm. 2001; 54: 214-215.

40. Russ H, McCleary D, Katimy R, et al. Development and Validation of a Stability-Indicating HPLC Method for the Determination of Tobramycin and Its Related Substances in an Ophthalmic Suspension. J Liq Chromatogr Relat Technol. 1998; 21: 2165-2181. doi:10.1080/10826079808006616

41. Wood MJ, Lund R, Beavan M. Stability of vancomycin in plastic syringes measured by high-performance liquid chromatography. J Clin Pharm Ther. 1995; 20: 319-325. doi:10.1111/j.1365-2710.1995.tb00705.x

42. Mathew M, Das Gupta V. Stability of Vancomycin Hydrochloride Solutions at Various $\mathrm{pH}$ Values as Determined by High-Performance Liquid Chromatography. Drug Dev Ind Pharm. 1995; 21: 257-264. doi:10.3109/03639049509048108

43. Das Gupta V, Stewart KR, Nohria S. Stability of vancomycin hydrochloride in $5 \%$ dextrose and $0.9 \%$ sodium chloride injections. Am J Hosp Pharm. 1986; 43: $1729-1731$.

44. Nahata MC, Miller MA, Durrell DE. Stability of vancomycin hydrochloride in various concentrations of dextrose injection. Am J Hosp Pharm. 1987; 44: 802-804.

45. Antoci Jr. V, Adams CS, Hickok NJ, et al. Antibiotics for local delivery systems cause skeletal cell toxicity in vitro. Clin Orthop. 2007; 462: 200-206. doi:10.1097/BLO.0b013e31811ff866

46. Johnson JD, Nessler JM, Horazdovsky RD, et al Serum and Wound Vancomycin Levels After Intrawound Administration in Primary Total Joint Arthroplasty. J Arthroplasty. 2017; 32: 924-928. doi:10.1016/j.arth.2015.10.015

47. Johnson JD, Nessler JM, Horazdovsky RD, et al. Serum and Wound Vancomycin Levels After Intrawound Administration in Primary Total Joint Arthroplasty. J Arthroplasty. 2017; 32: 924-928. doi:10.1016/j.arth.2015.10.015

48. Nelson CL, Hickmon SG, Skinner RA. Treatment of experimental osteomyelitis by surgical debridement and the implantation of bioerodable, polyanhydride-gentamicin beads. J Orthop Res. 1997; 15: 249-255.

49. Overstreet D, McLaren A, Calara F, et al. Local gentamicin delivery from resorbable viscous hydrogels is therapeutically effective. Clin Orthop. 2015; 473: 337-347 doi:10.1007/s11999-014-3935-9

50. McLaren AC, Castaneda P, Overstreet DJ. Post-Debridement Local Antimicrobial Delivery from PNDJ Gel is Effective for Orthopaedic Infections: A Rabbit Study. ORS Annual Meeting. 2017. p. 1319. Available: https://www.ors.org/Transactions/63/1319.pdf

51. Parvizi J, Gehrke T. Proceedings of the International Consensus Meeting on Periprosthetic Joint Infection. 2013; Available: https://www.efort.org/wpcontent/uploads/2013/10/Philadelphia_Consensus.pdf 